\title{
Rules versus discretion in food storage policies
}

\author{
Christophe Gouel
}

This article compares different policies in a rational expectations storage model with risk-averse consumers and missing insurance markets calibrated to represent a developing country. We consider an optimal storage policy under discretion and two optimal simple rules, a constant private storage subsidy and a price-band. The storage subsidy achieves welfare gains similar to the discretionary policy. The price-band maximizing social welfare is a price-peg scheme: the floor and ceiling prices are the same, and the capacity constraint represents $11 \%$ of the steady-state production level. It achieves three-quarters of the gains from the optimal policy under discretion.

Key words: discretion, food price stabilization, price volatility, storage.

JEL codes: Q11, Q18.

The author would like to thank the editor David Hennessy and three anonymous referees, as well as Jean-Marc Bourgeon, Benjamin Carton, Édouard Challe, Christopher Gilbert, Sébastien Jean, Michel Juillard, Stéphan Marette, and Brian Wright for helpful comments. This research was generously supported by the Knowledge for Change (KCP) Trust Fund, and by the AgFoodTrade and FOODSECURE projects, both funded under the $7^{\text {th }}$ Framework Programme for Research and Development, DG-Research, European Commission. The views expressed here are the sole responsibility of the author and do not reflect those of the European Commission.

This is a pre-copy-editing, author-produced PDF of an article accepted for publication in the American Journal of Agricultural Economics following peer review. The definitive publisher-authenticated version (Gouel C., 2013, 95(4), 1029-1044, American Journal of Agricultural Economics) is available online at: http://dx.doi.org/10.1093/ajae/aat016.

Christophe Gouel is a junior researcher, Public Economics, INRA. Email address: christophe.gouel@grignon.inra.fr. Phone number: +33144087277.

INRA, Économie Publique, AgroParisTech, 16 rue Claude Bernard, 75005 Paris, France, and CEPII 
Should food prices in poor countries be stabilized? This question was prompted by the riots during the 2007-08 food crisis and the continuing turmoil in agricultural markets. There is a lack of consensus among academics on this question (see, von Braun and Torero 2009, or Timmer, forthcoming, for supporters and Wright 2012 for arguments against). The policies being adopted by many countries would seem to indicate that policy-makers have already made-up their minds. Most countries use countercyclical trade policies to decrease the transmission of movements of world prices to their market (Anderson and Nelgen 2012b). China and India favor a system of trade and large-scale storage policies (Dorosh 2008). Middle East countries, which are very dependent on wheat imports, are working to establish large reserves (in the case of Saudi Arabia, equal to one year's consumption, World Bank and FAO 2012, p. 14). This move to more active stabilization policies may not be good news, given the mixed track record of such policies: storage policies tend to be very costly, to hinder the development of a private marketing system and, because of weak selling provisions, to lead to excessive stock levels (e.g., in India, Dorosh 2008).

Some of these problems are due to flawed policy design. In this article, we analyze the consequences of different storage policies when designed optimally by policy-makers whose objective is to stabilize food prices. Public storage policies are introduced into a rational expectations storage model, in order to stabilize markets beyond the efforts made by private agents. In traditional storage models, stabilization policies cannot increase welfare since there is no market imperfection (Scheinkman and Schechtman 1983). In our model, the additional stability brought by storage policies improves welfare because consumers are risk averse and insurance markets for food prices are missing. The use of a rational expectations storage model is motivated empirically by Cafiero et al. (2011), who show that this model performs well for explaining commodity price behavior.

This article characterizes optimal storage rules and distinguishes optimal state-contingent storage, which defines public storage as a nonlinear function of a state variable, from optimal simple rules, which are simpler policies defined by a limited set of parameters. For simple rules, we consider a constant subsidy to private storage and a price-band with capacity constraint on public stock levels. Since the present analysis addresses issues related to the design of storage policies, we do not try to reproduce the dynamics of a specific market; instead we calibrate the model to values typical of a cereals market in a developing country. For this calibration, if the parameters of the simple rules of stabilization are chosen so as to maximize welfare, a subsidy to private storage is able to achieve welfare gains similar to the optimal policy under discretion, while a price-band can achieve three-quarters of these gains. The implementation of price-band policies presents, however, two challenges: for slightly different price bounds and maximum stock level they may lead to welfare losses, and to achieve welfare gains they require the cooperation of private storers, who would seize any remaining profit opportunity.

This work is related to studies of commodity price stabilization schemes, for example, Miranda and Helmberger (1988) and Wright and Williams (1988a), which respectively analyze the behavior of priceband programs and compare several stabilization schemes applied frequently in agricultural policies. Both studies emphasize the importance of distinguishing between short- and long-run effects. Gardner and López (1996) compare policies aimed at stimulating private stockpiling and show that interest-rate subsidies are inefficient and that it is less costly to increase stabilization through direct storage subsidy. We draw on this literature although in our work the storage policies, or the parameters that define them, are optimal, while most existing work imposes exogenous policy rules. Previous studies also do not introduce rationales for public intervention, thus in these frameworks public interventions are almost certain to decrease welfare. 
Some authors have tried to combine stabilization policies with market imperfection, using the latter to justify the former. Brennan (2003) uses the limited development of financial markets, which implies prohibitively high private storage costs, to justify public intervention in the rice market in Bangladesh. She proposes stabilization policies to increase welfare, but does not design them to be welfare maximizing. A few works propose stabilization policies resulting from government optimization in reaction to market imperfections. Gardner (1979) considers that periods of high prices generate external costs not accounted for by private storers and proposes optimal storage policies that correct for these external costs. Wright and Williams (1982) design optimal public storage rules where government is unable to commit to not using a price ceiling, which creates a disincentive for private storage. We build on these works and extend analysis of optimal policies by comparing the outcomes of an optimal state-contingent policy with the outcomes of simple rules, such as storage subsidy or price-bands, which figure in policy discussion more frequently than fully optimal rules. This comparison between a fully optimal policy and optimal simple rules is influenced by related works in monetary and fiscal policy theory (Schmitt-Grohé and Uribe 2007; Taylor and Williams 2010), where simple rules are seen as a type of policy that is more easily implementable and more robust than a state-contingent policy. The literature on optimal dynamic policies is also used for the design of the optimal state-contingent storage policy, which is derived using the method in Klein, Krusell, and Ríos-Rull (2008).

The welfare framework we adopt is consistent with the literature assessing the welfare cost of price instability for consumers: an expected utility framework and the assumption of missing insurance markets (Turnovsky, Shalit, and Schmitz 1980; Helms 1985b). To simplify the exposition, other agents are assumed to be risk neutral. Based on this measure, the welfare of sufficiently risk-averse consumers decreases if price volatility increases.

\section{The model}

Our analysis follows the usual practice in studies of commodity price stabilization schemes (Miranda and Helmberger 1988; Wright and Williams 1988a) and employs a rational expectations storage model. This is a partial equilibrium model featuring a market for a storable commodity with a competitive storer, a producer whose output is subject to multiplicative shocks, and a final demand. ${ }^{1}$ We assume that consumers are risk averse and unable to insure. In our model, time is discrete and one period is assumed to correspond to one year. Thus, we focus on inter-annual storage and ignore issues related to seasonal fluctuations.

\section{Consumers}

The economy is populated with risk-averse consumers whose final demand for food has an isoelastic specification: $D\left(P_{t}\right)=\delta P_{t}^{\alpha} Y^{\eta}$, where $\delta>0$ is a normalization parameter; $P_{t}$ is the period $t$ price; and $\alpha$, with $\alpha<0$ and $\alpha \neq-1$, and $\eta \neq 1$ are the price and income elasticities. Income, $Y$, is assumed to be constant, which limits the number of state variables and allows a diagrammatic exposition of the results.

\footnotetext{
${ }^{1}$ One limitation of the standard storage model is the separability between consumption and production decisions, which is usually violated in developing countries (de Janvry and Sadoulet 2006). The effects of this non-separability on issues of price volatility have been discussed by Wright and Williams (1988b), Fafchamps (1992), and Finkelshtain and Chalfant (1997), among others. Non-separability tends to lead to higher gains from stabilization, because households' risk coping strategies increase market variability or hinder the development of market-oriented specializations. This literature could inspire further developments of this model, although it would bring additional complexity by increasing the number of state variables.
} 
Assuming there are only two goods and the second good is the numeraire, the integration of this demand function gives the following instantaneous indirect utility function (Hausman 1981)

$$
\hat{v}\left(P_{t}, Y\right)=\frac{Y^{1-\eta}}{1-\eta}-\delta \frac{P_{t}^{1+\alpha}}{1+\alpha} .
$$

This utility function has a relative risk aversion equal to the income elasticity of demand. To distinguish income elasticity from risk aversion, we follow Helms (1985a): we assume $\hat{v}\left(P_{t}, Y\right)$ to be positive and apply a monotonic transformation to the indirect utility function,

(2) $v\left(P_{t}, Y\right)=\frac{\left[\hat{v}\left(P_{t}, Y\right)\right]^{1+\theta}}{1+\theta}$,

with $v\left(P_{t}, Y\right) \rightarrow \ln \hat{v}\left(P_{t}, Y\right)$ as $\theta \rightarrow-1$. This specification is still consistent with an isoelastic demand function, but its coefficient of relative risk aversion is

$$
\rho\left(P_{t}, Y\right)=\eta-\theta \frac{Y^{1-\eta}}{\hat{v}\left(P_{t}, Y\right)},
$$

with $\theta$ indexing the degree of risk aversion.

For the sake of simplicity, the representative consumer is assumed to adopt hand-to-mouth behavior: he consumes current income and does not save to smooth out fluctuations. The dynamics are thus simplified, because the consumer's "cash on hand" does not have to be included as a state variable. This assumption ignores the role of self-insurance through saving. However, in practice, the level of self-insurance is limited and falls short of providing protection comparable with what complete markets would deliver, due inter alia to borrowing constraints and to the rather large budget share for staple food in many developing countries.

\section{Storers}

There is a single representative speculative storer, who is risk neutral and acts competitively. His activity is to transfer a commodity from one period to the next. Storing the quantity $S_{t}$ from period $t$ to period $t+1$ entails a purchasing cost, $P_{t} S_{t}$, and a storage cost, $k S_{t}$, with $k$ the unit physical cost of storage. We introduce also a per-unit constant subsidy $\zeta$, which is considered later as a possible stabilization tool. The benefits in period $t$ are the proceeds from the sale of previous stocks: $P_{t} S_{t-1}$. The storer follows a storage rule that maximizes his expected profit defined by

$$
\max _{\left\{S_{t+i} \geq 0\right\}_{i=0}^{\infty}} \mathrm{E}_{t}\left\{\sum_{i=0}^{\infty} \beta^{i}\left[P_{t+i} S_{t+i-1}-\left(P_{t+i}+k-\zeta\right) S_{t+i}\right]\right\},
$$

where $\mathrm{E}_{t}$ denotes the mathematical expectations operator, conditional on information available at time $t$, and $\beta$ is the discount factor. Accounting for the possibility of a corner solution (i.e., the non-negativity constraint of storage), the first-order condition of this problem yields the following complementary condition: ${ }^{2}$

$$
S_{t} \geq 0 \quad \perp \quad \beta \mathrm{E}_{t}\left(P_{t+1}\right)+\zeta-P_{t}-k \leq 0,
$$

2 Complementarity conditions in what follows are written using the "perp" notation $(\perp)$. This means that both inequalities must hold, and at least one must hold with equality. 
which means that inventories are null when the marginal cost of storage is not covered by the expected marginal benefits; for positive inventories, the arbitrage equation holds with equality. So we have a situation of a stabilizing speculation: the storer buys when prices are low and when rationally he expects that they will become higher later.

\section{Producers}

A representative producer makes his productive choice one period before bringing output to market. He puts in production in period $t$ a level $H_{t}$ for period $t+1$, but a multiplicative disturbance (e.g., a weather disturbance) affects final production. The producer chooses the production level by solving the following maximization of expected profit:

$$
\max _{\left\{H_{t+i}\right\}_{i=0}^{\infty}} \mathrm{E}_{t}\left\{\sum_{i=0}^{\infty} \beta^{i}\left[P_{t+i} \varepsilon_{t+i} H_{t+i-1}-\Psi\left(H_{t+i}\right)\right]\right\},
$$

where $\Psi\left(H_{t}\right)$ is the cost of planning the production $H_{t}$ and $H_{t} \varepsilon_{t+1}$ is the realized level. $\varepsilon_{t+1}$ is the realization of an i.i.d. stochastic process of mean 1 exogenous to the producer, which follows a translated beta distribution. The solution of this problem is the following Euler equation:

$$
\beta \mathrm{E}_{t}\left(P_{t+1} \varepsilon_{t+1}\right)=\Psi^{\prime}\left(H_{t}\right) .
$$

This equation has a straightforward interpretation: it is the equality between the marginal cost of production and the expected discounted marginal benefit of one unit of planned production. We assume decreasing returns to scale because a production increase requires the use of less fertile lands. The production cost function follows an isoelastic form

$$
\Psi(H)=h \frac{H^{1+\mu}}{1+\mu},
$$

where $h>0$ is a scale parameter and $\mu \geq 0$ is the inverted supply elasticity.

\section{Recursive equilibrium}

At the beginning of each period, three predetermined variables define the state of the model: $S_{t-1}, H_{t-1}$ and $\varepsilon_{t}$. They can be combined in one state variable, private availability, $A^{\mathrm{P}}$, the sum of production and private carry-over:

$$
A_{t}^{\mathrm{P}} \equiv S_{t-1}+H_{t-1} \varepsilon_{t}
$$

When government pursues food price stabilization through public storage, we can also define total availability, $A^{\mathrm{T}}$, as the sum of private availability and public carry-over denoted as $S^{\mathrm{G}}$ :

$$
A_{t}^{\mathrm{T}} \equiv S_{t-1}^{\mathrm{G}}+S_{t-1}+H_{t-1} \varepsilon_{t} .
$$

Accounting for the presence of public stockholding, market equilibrium can be written as

(11) $\quad A_{t}^{\mathrm{T}}=A_{t}^{\mathrm{P}}+S_{t-1}^{\mathrm{G}}=D\left(P_{t}\right)+S_{t}+S_{t}^{\mathrm{G}}$. 
From the above, we can define the recursive equilibrium of the problem without public intervention:

DEFInITION. In the absence of a stabilization policy (i.e., $\zeta=S^{\mathrm{G}}=0$ ), a recursive equilibrium is a set of functions, $S\left(A^{\mathrm{P}}\right), H\left(A^{\mathrm{P}}\right)$ and $P\left(A^{\mathrm{P}}\right)$, defining storage, production and price over the state $A^{\mathrm{P}}$ and a transition (9) such that (i) storer solves (4), (ii) producer solves (6), and (iii) the market clears.

\section{Designing optimal stabilization policies}

Policies start at period 0 and are unanticipated by the agents. The parameters of stabilization policies are determined by maximizing a social welfare function that aggregates consumers' utility, other agents' surpluses and fiscal cost. Initial availability is taken as the deterministic steady-state level and initial private stocks are assumed to be null. Government is assumed to be able to manage storage facilities at the same costs as private storers.

\section{Social welfare function}

In a partial equilibrium model, the welfare of all agents must be accounted for when maximizing social welfare. Whereas agents' surplus is generally used to carry out this analysis, this is not possible for consumers: as shown by Helms (1985b), surplus is not a correct welfare measure for risk-averse agents. Following Helms (1985b), an appropriate monetary measure for the change in consumer welfare is the $e x$ ante equivalent variation, $E V$, calculated using the following implicit definition

$$
\mathrm{E}_{0}\left\{\sum_{t=0}^{+\infty} \beta^{t}\left[v\left(\tilde{P}_{t}, Y+E V\right)-v\left(P_{t}, Y\right)\right]\right\}=0,
$$

where $\tilde{P}_{t}$ refers to price in period $t$ without policy intervention. Given this definition, we can express the social welfare function in period 0 by analogy to a traditional sum of surpluses as the sum of consumer's equivalent variation and other agents' surplus: ${ }^{3}$

$$
\frac{E V}{1-\beta}+\mathrm{E}_{0} \sum_{t=0}^{\infty} \beta^{t}[\underbrace{P_{t} H_{t-1} \varepsilon_{t}-\Psi\left(H_{t}\right)}_{\text {Producer's surplus }}+\underbrace{P_{t} S_{t-1}-\left(P_{t}+k-\zeta\right) S_{t}}_{\text {Storer's surplus }}-\text { Cost }_{t}]
$$

where Cost is the fiscal cost of the policy.

The cost of the policy is either the amount of the subsidies given to private storers or the cost of carrying public stock, which is similar to the profit from private storage. It is equal to the difference between purchasing plus storage costs of new stock and the revenue derived from selling previous period stock, $S_{t-1}^{\mathrm{G}}$ :

$$
\operatorname{Cost}_{t}=\zeta S_{t}+\left(P_{t}+k\right) S_{t}^{\mathrm{G}}-P_{t} S_{t-1}^{\mathrm{G}}
$$

Using equations (9) and (14), social welfare can be simplified as

(15) $\frac{E V}{1-\beta}+\mathrm{E}_{0} \sum_{t=0}^{\infty} \beta^{t}\left[P_{t}\left(A_{t}^{\mathrm{P}}+S_{t-1}^{\mathrm{G}}\right)-\Psi\left(H_{t}\right)-\left(P_{t}+k\right)\left(S_{t}+S_{t}^{\mathrm{G}}\right)\right]$,

\footnotetext{
${ }^{3}$ Note that, were income elasticity and relative risk aversion equal to zero, this definition would make $E V$ equal to the annualized expected consumers' surplus, so that the social welfare function below would actually be the sum of the surpluses.
} 
In the social welfare function, the subsidy is positive in storers' profit and negative in public cost. Consequently, the two subsidy terms are offsetting and can be dropped from the social welfare equation.

While theoretically exact, this equation cannot be used as the objective for an optimal policy design problem, because the equivalent variation renders it intractable. It is defined implicitly and depends on all future price realizations, with and without policy. To obtain a tractable representation of social welfare, we approximate the first term in equation (12) to the first-order around the path followed without intervention. ${ }^{4}$ It gives

$$
E V \approx \frac{1-\beta}{w} \mathrm{E}_{0} \sum_{t=0}^{\infty} \beta^{t}\left[v\left(P_{t}, Y\right)-v\left(\tilde{P}_{t}, Y\right)\right]
$$

where $w=(1-\beta) \mathrm{E}_{0} \sum_{t=0}^{\infty} \beta^{t} v_{Y}\left(\tilde{P}_{t}, Y\right)$ is the discounted sum of marginal utility of income.

After subtracting from (16) the term reflecting consumer's utility in the situation without intervention, $v\left(\tilde{P}_{t}, Y\right)$, which is independent from policy choice, the objective function can thus be expressed as

$$
\mathrm{E}_{0}\left\{\sum_{t=0}^{\infty} \beta^{t}\left[v\left(P_{t}, Y\right) / w+P_{t}\left(A_{t}^{\mathrm{P}}+S_{t-1}^{\mathrm{G}}\right)-\Psi\left(H_{t}\right)-\left(P_{t}+k\right)\left(S_{t}+S_{t}^{\mathrm{G}}\right)\right]\right\} .
$$

\section{Optimal state-contingent policy}

State-contingent public storage policies are policies in which storage decisions are based on the state of the system. For optimal state-contingent policies, the literature usually distinguishes between optimal policies under commitment and optimal policies under discretion (Clarida, Galí, and Gertler 1999). An optimal policy under commitment is a rule of intervention that maximizes the expected intertemporal social welfare with the perspective of the initial period. In contrast, a buffer-stock manager operating under discretion chooses the public stock level by reoptimizing every period. Thus, the policy under commitment is likely to be time-inconsistent because it would be different if policy makers were to reoptimize after the initial period (Kydland and Prescott 1977). For ease of exposition, we restrict our analysis to the policy under discretion, which has the advantage of being a function only of current state variables, while the policy under commitment can depend also on all past history (see Gouel 2013, for the analysis of a storage policy under commitment).

For this optimal policy under discretion, we consider a time-consistent Markovian policy (see, e.g., Klein, Krusell, and Ríos-Rull, 2008, and Ambler and Pelgrin, 2010, for characterizations of the equilibrium concept). The government accounts, in each period, for agents' responses to the policy (i.e., their first-order conditions). The choice concerns current-period endogenous variables and depends only on the current state, total availability. The value of future variables is taken as given based on rational expectations about them. So, at each period, the policy maker maximizes the conditional expected sum of the discounted social welfare function subject to the equations defining the rational expectations equilibrium:

$$
\max _{\substack{S_{t} \geq 0, H_{t}, P_{t}, A_{t+1}^{\mathrm{T}}, S_{t} \geq 0}} \mathrm{E}_{t} \sum_{i=0}^{\infty} \beta^{i}\left[v\left(P_{t+i}, Y\right) / w+P_{t+i} A_{t+i}^{\mathrm{T}}-\Psi\left(H_{t+i}\right)-\left(P_{t+i}+k\right)\left(S_{t+i}+S_{t+i}^{\mathrm{G}}\right)\right]
$$

\footnotetext{
${ }^{4}$ It can be shown (following Wright and Williams 1988b, Appendix) that the equivalent variation is of the same order of magnitude as the change in the variance of price, so the square of the equivalent variation is of a smaller order for a small price stabilization and second-order terms in the approximation can be neglected. This is confirmed by the results below, in which the welfare gains proved to be very low compared to income, and in the supplementary appendix where the approximation error is assessed.
} 
subject to equations (5), (7), (10) and (11), $A_{t}^{\mathrm{T}}$ given, and anticipating $\left\{S_{t+i}, H_{t+i}, P_{t+i}, A_{t+i+1}^{\mathrm{T}}, S_{t+i}^{\mathrm{G}}\right\}$ for $i \geq 1 .{ }^{5}$ For conciseness, the dynamic programming problem of this optimal policy problem is presented in a supplementary appendix available online. It is derived following the methodology developed in Klein, Krusell, and Ríos-Rull (2008).

\section{Optimal simple rules}

Simple rules are rules of public behavior providing a simple feedback between observable variables and policy instruments. To be simple, these rules have to be defined by a small set of parameters, and not be infinite-dimension objects like the state-contingent policy defined above. We consider two simple rules commonly discussed in the literature: a constant subsidy for storage, which aims at stimulating private storers' activity, and a price-band defended by a public stock. They are defined respectively by one and three parameters, which are chosen to maximize intertemporal social welfare.

In contrast to a state-contingent policy, these rules are not fully flexible with respect to the state of the system, so they do not provide an optimal policy for each situation. Despite this limited flexibility, simple rules are discussed at length in the literature on monetary and fiscal policy, which recognizes their good properties. Simple rules entail commitment. They also tend to be more robust than globally optimal policies. The need for robustness emerges from our limited knowledge of the way the economy works. The literature does not completely agree about the best explanations for agricultural price dynamics; and it might be better to find a simple rule that is robust across a variety of frameworks than to design optimal policies that are model-specific and whose good properties do not transfer well to another model (Levin, Wieland, and Williams 2003). Gardner (1979) analyzes this issue of robustness in a situation where ignorance is related to the level of negative externality created by high commodity prices. $\mathrm{He}$ shows, in that context, that a price-band policy may be preferable to an optimal stockpiling policy. In the present study, we do not analyze the robustness of simple rules; rather we consider, in a given framework, how simple rules compare with an optimal state-contingent rule.

Unlike state-contingent rules, the parameters of optimal simple rules are not determined by solving the first-order conditions of a maximization problem. The parameters that need to be determined are constant, and maximizing over constant variables creates terms with infinite sums that are difficult to handle. To find these parameters, we apply a method similar to the nested fixed-point approach in Rust (1987). This consists of two nested algorithms. The outer algorithm adjusts the policy parameters of the rule to maximize intertemporal social welfare by applying an optimization solver. For each iteration of the outer algorithm, the inner algorithm (described in supplementary appendix) solves the rational expectations problem for the new set of policy parameters. With respect of the outer algorithm, the optimal subsidy can be found easily with any nonlinear programming solver. For the price band, however, the flatness of the social welfare function around the optimum and the approximation errors inherent in the solution of a rational expectations model create the risk of arriving at a local solution that is not globally optimal. So the optimal price band is found by combining a grid search for identifying good starting points with a nonlinear programming solver from the multiple starting points. ${ }^{6}$

\footnotetext{
${ }^{5}$ For tractability, we use as objective for the optimal policy under discretion the structure of the social welfare function derived in period 0 . It relies on a first-order approximation of $E V$ at time 0 , given by equation (16). Using this first-order approximation at each period implicitly assumes $(1-\beta) \mathrm{E}_{t} \sum_{i=0}^{\infty} \beta^{i} v_{Y}\left(\tilde{P}_{t+i}, Y\right)$ to be equal to $w$, its value at $t=0$, from which it does not depart by more than one percent in the simulations below.

${ }^{6}$ For more precision, see the MATLAB program files in supplementary materials.
} 


\section{Storage subsidy}

A constant storage subsidy is a very simple policy, since it consists only of giving private storers a constant subsidy $\zeta$ for each stockpiled unit. The intervention does not vary and there is no feedback between observations and policy actions, the underlying idea being that private storers are good at reacting to the economic situation, but provide too little stabilization and should be encouraged to do more. The subsidy makes physical speculation more profitable and increases stock levels, which stabilizes prices more than in the absence of subsidy. Since there is no public storage, storage subsidy makes private availability equal to total availability.

The optimal subsidy is the value maximizing the conditional expected sum of the discounted social welfare at period 0 , defined by (17), subject to (5), (7), (9) and (11).

\section{Price-band}

A price-band program is a controversial policy. On the one hand, it is probably the most commonly proposed stabilization instrument in the policy arena. Its simplicity is appealing to policy-makers. It consists of defining two prices: a floor and a ceiling price, which are defended by a public stock. It is a function of the current price, which, in practice, is more easily observable than availability. Keynes (1974) proposed such a scheme, in 1942, as a way to stabilize internationally traded raw materials and it was used subsequently in three international commodity agreements: cocoa, rubber and tin (Gilbert 1996). BULOG, the Indonesian Food Logistics Agency, has defended with some success in the rice market a floor price to protect farmers and a ceiling price to protect consumers (Timmer 1997).

On the other hand, theoretical analyses of price-bands have led to much criticism (Miranda and Helmberger 1988; Williams and Wright 1991, Ch. 13-14). A major critique is that price-band programs tend to produce over-accumulation of stock since nothing is sold until the ceiling price is reached. They can lead to explosive stock levels in the case of poor floor and ceiling price combinations. Finally, policy-makers expect these programs to stabilize prices between the bounds, but the models predict that, on the contrary, prices tend to get stuck at the bounds, challenging them continually, and rarely lie between them. ${ }^{7}$

In our implementation of a price-band, to avoid extreme over-accumulation, we place a capacity constraint, $\bar{S}^{\mathrm{G}}$, on public storage. ${ }^{8}$ Once public stock reaches its capacity constraint, public intervention ceases and the floor price is no longer defended until there is a decrease in the public stock. Such a policy is governed by three parameters: a floor price, $P^{\mathrm{F}}$, a ceiling price, $P^{\mathrm{C}}$, and a capacity constraint. The parameters are determined optimally to maximize welfare, so if the capacity constraint does not improve welfare, it will be given a very high value thus making it redundant.

The behavior of a price-band with capacity constraint obeys some simple principles. When the price is above the floor price, there is no accumulation of public stock:

$$
P_{t}>P^{\mathrm{F}} \Rightarrow \Delta S_{t}^{\mathrm{G}} \leq 0
$$

Likewise, when the price is below the ceiling price, government does not sell stock:

$$
P_{t}<P^{\mathrm{C}} \Rightarrow \Delta S_{t}^{\mathrm{G}} \geq 0
$$

\footnotetext{
${ }^{7}$ For a non-technical summary of all criticisms, see Wright (2012).

8 Alternatively, a maximum level of public spending could have been defined. However, a storage capacity constraint is simpler to express mathematically.
} 
When the capacity constraint is reached, the floor price is not defended and the price can decrease below it:

$$
P_{t}<P^{\mathrm{F}} \Rightarrow \Delta S_{t}^{\mathrm{G}}=\bar{S}^{\mathrm{G}}-S_{t-1}^{\mathrm{G}} .
$$

Finally, the ceiling price is not defended when the public stock is exhausted:

$$
P_{t}>P^{\mathrm{C}} \Rightarrow \Delta S_{t}^{\mathrm{G}}=-S_{t-1}^{\mathrm{G}} .
$$

These four conditions are expressed in a concise mathematical formulation as two mixed complementarity equations in the supplementary appendix.

Under a price-band policy, the problem has two state variables: private availability, defined by (9), and previous-period public stock. Public stock appears as a separate state variable because it is not directly available for the market. It is used only to defend the price-band and so does not play the same role as private stock and production, which can be summed together.

\section{Results}

The rational expectations storage model is known to lack a closed-form solution. It has to be approximated numerically. (The interested reader can find in a supplementary appendix a description of the numerical method used.)

\section{Calibration}

Table 1 presents the parameters used to calibrate the model. The parameters are set such that, at the model's non-stochastic steady state, price, production, consumption and availability are equal to 1 . An annual interest rate of $5 \%$ is used for discounting.

Table 1. Parameterization

\begin{tabular}{llr}
\hline Parameter & Economic interpretation & Assigned value \\
\hline$\beta$ & Annual discount factor & 0.95 \\
$\eta$ & Income elasticity & 0.5 \\
$\alpha$ & Own-price demand elasticity & -0.4 \\
$\gamma$ & Commodity budget share & 0.15 \\
$\mu$ & Inverse of supply elasticity & 2 \\
$Y$ & Income & 6.67 \\
$\delta$ & Normalization parameter of demand function & 0.39 \\
$h$ & Normalization parameter of production cost function & 0.95 \\
$\theta$ & Parameter defining risk aversion & -2.62 \\
$k$ & Physical storage cost & 0.06 \\
\hline
\end{tabular}

Seale and Regmi (2006) estimate elasticities for food consumption across 144 countries. From their research, we choose cereal elasticities typical of low-income countries: -0.4 for price elasticity and 0.5 for income elasticity. We assume that, at the steady state, consumers spend $\gamma=15 \%$ of their income on the staple (a value intermediate between what is observed for rice consumption in poor and affluent households in Asia, Asian Development Bank 2008). Since steady-state consumption and price are all 
equal to 1 , income, which is assumed to be constant, is equal to the inverse of the commodity budget share, $1 / \gamma$. We assume at the steady state a relative risk aversion parameter of 2 , implying $\theta=-2.62$ (see supplementary appendix for a sensitivity analysis of these parameters).

We follow Brennan (2003) and assume a per-unit storage cost of $6 \%$ of the steady-state price (i.e., $k=0.06)$. Combined with the opportunity cost, this physical storage cost entails an overall steady-state storage cost equal to $11.3 \%$ of the steady-state price.

Estimation of the price elasticity of supply produces controversial results (Rao 1989; Schiff and Montenegro 1997). We choose a value of 0.5 , often produced by related studies, and in the supplementary appendix analyze the sensitivity of results to this value. For this elasticity, we have $\mu=2$. There is no evidence on which to base the choice of a particular probability distribution for yield at the country level. Thus, we assume that the random productive shocks $\varepsilon$ follow a beta distribution. The beta distribution has the advantage of being empirically supported and popular in stochastic yield modeling at the local level (see, among others, Nelson and Preckel 1989; Babcock and Hennessy 1996) and of having bounded support, which is computationally convenient. We assume the distribution to have shape parameters 2 and 2 , which makes it unimodal at 0.5 , and symmetric. The distribution is translated and rescaled to vary between 0.75 and 1.25 , implying a coefficient of variation of $11.2 \%$. The sensitivity of the results to the shape of the distribution is analyzed in the supplementary appendix.

\section{Storage behavior}

Without a storage policy, private storers (solid line in figure 1) do not stock anything for low availability (the threshold is close to the steady-state availability level, 1) and increase the level of stock with market availability above the threshold. When normal consumption is satisfied, any additional quantity in the market tends to lower prices. Speculators take advantage of these lower prices to accumulate stock that can be sold later when availability is low and prices are higher. If government intervenes, total stock is always higher for a given availability than without intervention.

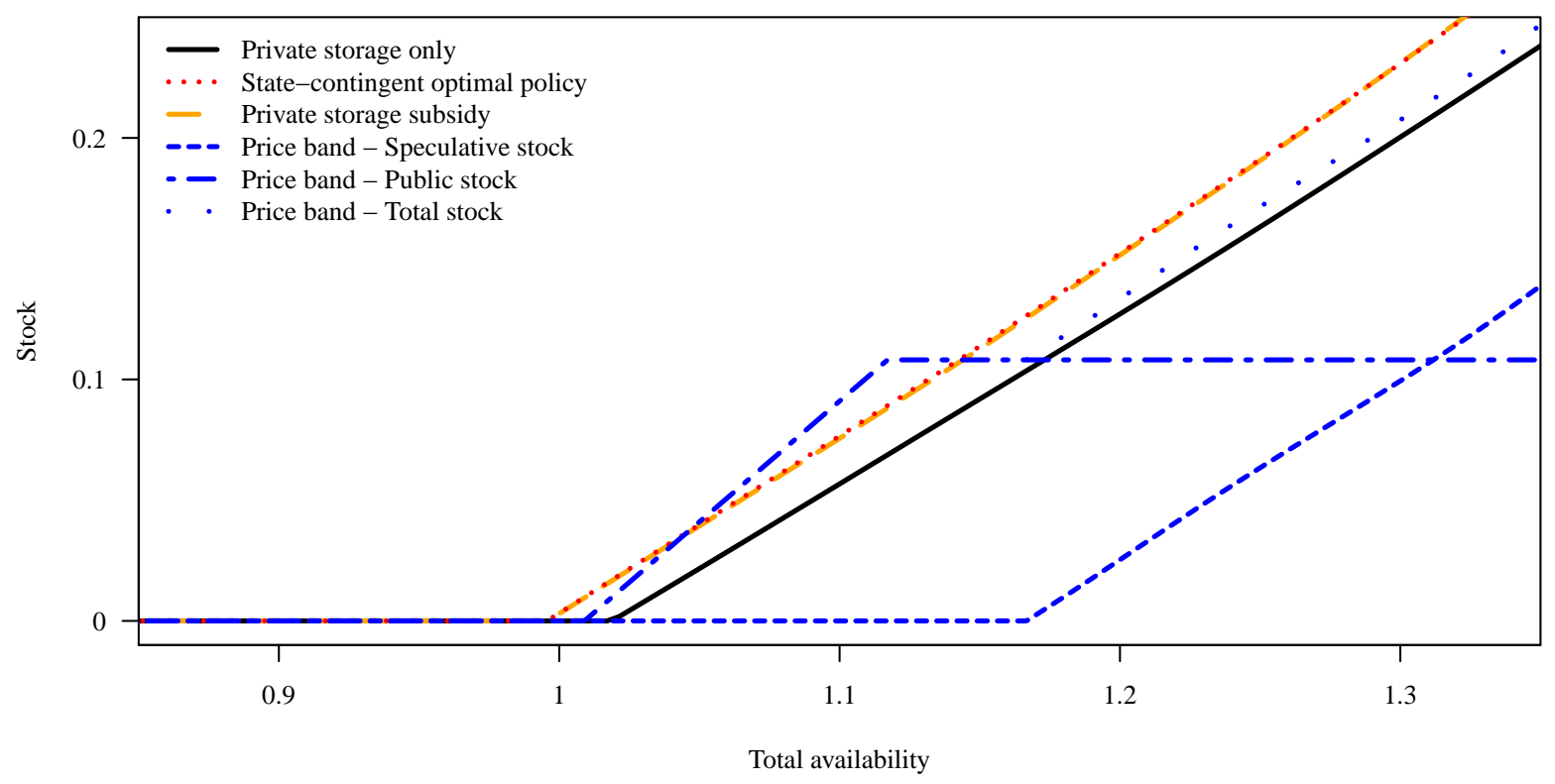

Figure 1. Storage rules 


\section{Optimal state-contingent public storage}

Optimal public storage under discretion (dotted line in figure 1) completely crowds out private storage. Considering consumers' risk aversion implies that the socially optimal level of price instability is lower than without intervention. Since private storers cover their storage cost by the difference between their purchasing and selling prices, the additional stability brought by public stockpiling is likely to reduce their profit opportunity. Given that the optimal storage rule is always higher than the private storage rule without intervention, the arbitrage condition of private storers (5) is never satisfied and they are crowded out by the policy.

\section{Storage subsidy}

A policy of subsidy for private storage shifts the storage rule to the left (long-dashed curve in figure 1). It produces a storage rule that is very close to the optimal, state-contingent, discretionary rule. The optimal level of subsidy is 0.044 , which represents $39 \%$ of steady-state storage cost (physical cost plus opportunity cost for a price of 1 ).

\section{Price-band}

When the price-band policy is designed to maximize welfare, the optimal floor and ceiling prices collapse in a single price, equal to 0.978 . This kind of policy, a floor-price with a capacity constraint on the public stockpile, is analyzed in Salant (1983), Williams and Wright (1991, Ch. 14) and Brennan (2003), and described as a "price-peg". Government defends the target price by building stock, but when the price is above the target price, public stock is sold. This behavior is as expected under a price-band except that the two bounds are merged. This result contrasts with the intuition that to protect consumers, stocks should be accumulated at low prices and used to prevent prices from exceeding a limit. However, it is in line with the theory on price-band programs. Miranda and Helmberger (1988, table 3) show that the deadweight loss from a price-band program is lowest for a zero bandwidth. Williams and Wright (1991, Ch. 14) find that the price-peg scheme entails smaller losses than either a price-band or a simple floor-price. In their view the price-band scheme tends to result in over-accumulation caused by the absence of public stock sales while the price is between the bounds. A price-band policy does not try to stabilize the price within bounds, but only to prevent the price from exceeding them. Under a price-band scheme, public stock is not considered a potential source of supply, but only a means for defending the bounds, so stock can reach very high levels if bounds are set inappropriately. A price-peg scheme avoids this by putting stock on the market as soon as it is accumulated and excessive accumulation is also avoided by the imposition of a capacity limit.

The optimal coincidence of floor and ceiling prices may be sensitive to one assumption rarely considered in the storage literature, but probably relevant: the transaction costs involved in adjusting stock levels (Chavas, Despins, and Fortenbery 2000; Bobenrieth, Bobenrieth, and Wright 2004). For example, for storage in a silo, grain has to be cleaned and the temperature reduced to prevent pest infestation, which entails costs. These adjustment costs may justify a small wedge between the two prices to avoid too many stock level adjustments. 
Under the price-peg program, speculators still find profit opportunities (see the short-dashed curve in figure 1), when public storage is limited by its capacity constraint. ${ }^{9}$ For high availability, government cannot defend the price-peg, because its stock bumps into its capacity constraint, optimally set at 0.11 . At the threshold point where the capacity constraint becomes binding, there is a clear tendency for over-accumulation. The storage rule under the price-peg scheme is above all other rules and the marginal propensity to store is 1 . When the capacity constraint is reached, there is a situation where, even if availability increases, no stock, public or private, is added to the existing stock. Private storers start to accumulate for higher levels of availability.

This interaction between speculative storage and public stock is illustrated in the simulation in figure 2 . Public stock frequently reaches its capacity limit. This implies that the price-peg program does not work as expected for a traditional price-band. The target price is not seriously defended since public stock is often at its limit. By its nature, a price-peg cannot be defended indefinitely if the initial public stock is finite, and without the capacity constraint the accumulation of public stock under this policy could be explosive given the high level of the intervention price. In reality, the price-peg is a way to define a rule allowing the accumulation of public stocks to protect consumers from price fluctuations; it is not a target that government seriously tries to support.



Figure 2. Simulation of total availability (right $y$-axis), public stock and private stock (left $y$-axis) under the optimal price-band program

\section{Dynamics under food price stabilization policies}

In this section, we analyze the transitional behavior following policy implementation. We do not analyze the dynamics of endogenous variables for specific simulations, only their expectations while they converge to their new asymptotic distributions. In any period, the realized values may be above or below these expectations. Since the policies involve higher mean stock levels than without intervention, they begin with a phase of stock build-up. The transition is illustrated in figure 3 with the dynamics of mean total stock and mean prices. The average stock level increases by more than one half under an optimal policy. The lowest stock level increase occurs for the price-peg policy and the highest for the optimal policy under discretion.

\footnotetext{
${ }^{9}$ For a price-peg defined by other parameters, it is also possible to observe speculators' activity at low availability where they can carry out speculative attacks on the public stock (Salant 1983).
} 

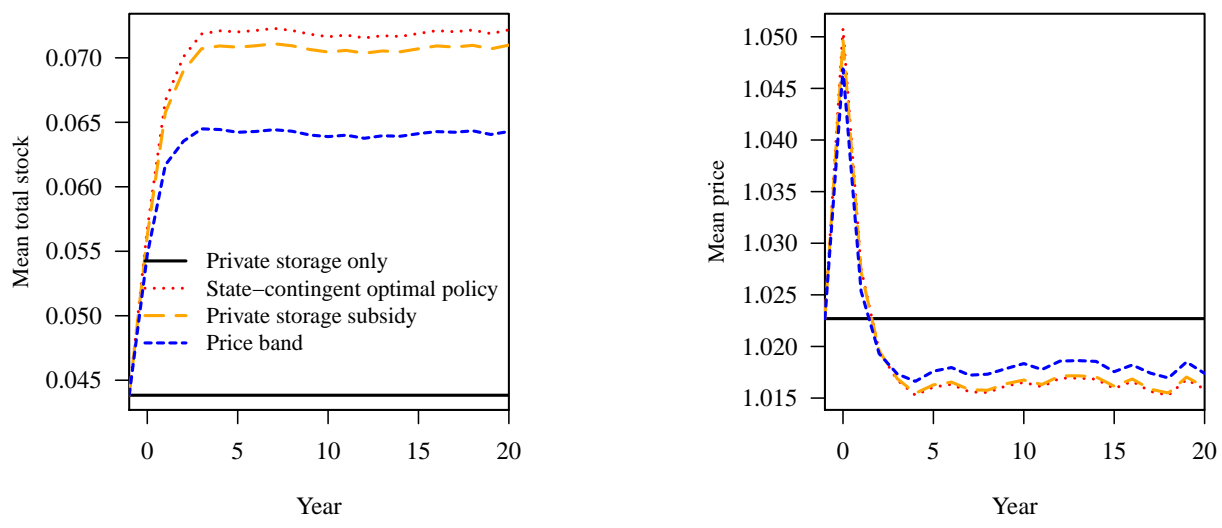

Figure 3. Transitional dynamics.

Note: Before period 0, the system is on the asymptotic distribution of the model without public intervention. The unexpected policy is announced and starts in period 0. (Obtained by Monte Carlo simulation as the average over 100,000 simulated paths.)

In the first years, the purchases made to accumulate stocks push mean prices above their long-run values. After a few years, mean prices drop below the value without public intervention. Because of the convexity of the demand curve, the additional storage decreases higher prices more than it increases low prices. Hence, stabilization entails lower mean prices and the effects are almost identical for all policies.

The dynamic welfare effects of the policies are presented in table 2. Consumers' gains are given by the ex-ante per-period equivalent variation, $E V_{0}$, as expressed in equation (12). Producers' gains are the annualized changes in expected profit from equation (6). Government outlays are the annualized expected sum of discounted costs defined by equation (14). ${ }^{10}$ Changes in storers' surpluses are ignored since storers operate, on average, at zero profit and we assume no stock at the first period. Welfare increases for all policies.

Table 2. Welfare Results on Transitional Dynamics

\begin{tabular}{lcrr}
\hline & State-contingent policy & Subsidy & Price-band \\
\hline Consumers' gains & 0.352 & 0.343 & 0.278 \\
Producers' gains & 0.035 & 0.030 & -0.007 \\
Government outlays & 0.303 & 0.290 & 0.209 \\
Total gains & 0.084 & 0.084 & 0.062 \\
\hline
\end{tabular}

Note: Welfare gains as a percentage of the steady-state commodity budget share.

Most welfare results differ little across policies. Total gains are small. They do not exceed $0.084 \%$ of the commodity budget share. Producers experience small welfare changes. They benefit from the first-period increased price, but lose from the long-run mean price decrease. After discounting, the first-period benefits dominate results for the state-contingent policy and the subsidy, while the long-run costs decrease producers' welfare for the price-band. Consumers' gains from the policies are much larger than total gains. These gains come mostly at the expense of the taxpayers.

\footnotetext{
10 Welfare terms are all discounted infinite sums. They are calculated by transformation to a recursive formulation and value function iteration.
} 
An optimal constant subsidy for private storage achieves welfare results close to the optimal policy under discretion. This is not surprising given how close the two storage rules are (figure 1). ${ }^{11}$ Compared to the other policies, subsidy stands out: it is much simpler, achieves similar gains, and implies limited public intervention, given that policy implementation is decentralized to private agents. It means that private storers adopt behavior that is very similar to what is socially optimal. They just need some incentives to achieve it.

The price-band, which in our case collapses to a price-peg mechanism, is the worst of the three policies. Nevertheless, it reaps almost three-quarters of the welfare gains from the optimal policy under discretion. The relatively good performance of the price-band should be linked to the optimal choice of parameters. Table 3 illustrates what would be the social welfare changes from price-bands with different parameters. It considers three floor prices and three limits on public storage. Ceiling prices are chosen to illustrate price-pegs, symmetric price-bands and ceilings at the deterministic steady state, which is equal to 1 . It appears that the capacity constraint is essential for reaching the highest gains; with either no constraint or a high one, most parameter combinations entail welfare losses. Despite the intuitive appeal of defining a policy by a mean price with symmetric bounds, symmetric price-bands do not perform well, since the higher the upper bound, the longer the food is stored. Welfare tends to decrease with the ceiling price, and price-peg schemes achieve the highest welfare levels. The welfare changes presented in table 3 should be seen as a warning against storage rules based on a price-band. Unless the key parameters of the economy are well understood and there is an incentive to make the optimal choice of scheme, this kind of intervention may well reduce welfare.

Table 3. Social Welfare Changes from Non-Optimal Price-Band Policies

\begin{tabular}{cccrc}
\hline & & \multicolumn{3}{c}{ Capacity constraint on public stock } \\
\cline { 3 - 5 } Floor price & Ceiling price & \multicolumn{1}{c}{0.15} & 0.3 & $+\infty$ \\
\hline 0.85 & 0.85 & 0.007 & 0.019 & 0.019 \\
0.85 & 1.00 & 0.018 & -0.004 & -0.002 \\
0.85 & 1.15 & -0.054 & -0.093 & -0.100 \\
0.90 & 0.90 & 0.039 & 0.044 & 0.038 \\
0.90 & 1.00 & 0.030 & -0.062 & -0.128 \\
0.90 & 1.10 & -0.088 & -0.414 & -1.001 \\
0.95 & 0.95 & 0.060 & -0.038 & -0.194 \\
0.95 & 1.00 & 0.036 & -0.192 & -0.742 \\
0.95 & 1.05 & -0.019 & -0.393 & -1.661 \\
\hline
\end{tabular}

Note: Welfare gains as a percentage of the steady-state commodity budget share.

Speculative storers are essential for the good functioning of an optimal price-band. Under a price-band program government intervenes only to defend the bounds and does not consider volatility inside and outside the bounds. Because there are profit opportunities beyond the bounds, speculators bring additional stabilization. They stock for prices below the target. Hence they provide some stabilization in situations where the public storage rule is inactive. Without speculative storage, the same price-peg policy would reduce total welfare by $0.85 \%$ when compared to the laissez-faire situation. This is 10 times the gains from an optimal stabilization policy. It demonstrates that, before contemplating the potential benefits from

${ }^{11}$ For this particular calibration, welfare from the optimal policy under discretion is marginally superior to the one under a subsidy. However, there are cases where it will lead to lesser gains, because the policy under discretion is designed by reoptimizing welfare at each period, while the subsidy is optimal for the initial period (see the sensitivity analysis in the supplementary appendix for illustrations of such situations). 
a public storage policy, much more could be gained by ensuring that private agents can operate freely and in a predictable policy environment, which is far from being secured in many developing countries (Tschirley and Jayne 2010).

\section{The long-run effects of stabilization policies}

On the asymptotic distribution, stabilization policies decrease the occurrence of low prices (see price quantiles in table 4), because there is more storage in situations of high availability than without public intervention. This effect is less marked for the price-band policy since public stockpiling starts at higher availability levels. Conversely, sale of this additional storage accumulated at high availability reduces the frequency of very high prices.

Table 4. Descriptive Statistics on the Asymptotic Distribution

\begin{tabular}{|c|c|c|c|c|}
\hline & Laissez-faire & State-contingent policy & Subsidy & Price-band \\
\hline Mean price & 1.023 & 1.016 & 1.016 & 1.018 \\
\hline Coefficient of variation of price & 0.206 & 0.169 & 0.170 & 0.178 \\
\hline Correlation between price and production & -0.810 & -0.718 & -0.720 & -0.763 \\
\hline \multicolumn{5}{|l|}{ Price quantiles } \\
\hline $1 \%$ & 0.798 & 0.836 & 0.838 & 0.799 \\
\hline $25 \%$ & 0.879 & 0.908 & 0.906 & 0.894 \\
\hline $50 \%$ & 0.935 & 0.960 & 0.959 & 0.978 \\
\hline $75 \%$ & 1.117 & 1.047 & 1.050 & 1.062 \\
\hline $99 \%$ & 1.708 & 1.637 & 1.640 & 1.649 \\
\hline $99.9 \%$ & 1.865 & 1.814 & 1.815 & 1.822 \\
\hline Mean total stock & 0.044 & 0.072 & 0.071 & 0.064 \\
\hline
\end{tabular}

Note: statistics calculated over 1,000,000 sample observations from the asymptotic distribution.

In the price-peg policy, the target price is close to the steady-state price. This means that, without public intervention, prices are often below this target, implying that, under a price-peg, intervention will be frequent. Under a price-peg, 35\% of the time prices are below the target, $31 \%$ they are on it, and $33 \%$ they are above it. Government defends the target by accumulating or selling stocks $31 \%$ of the time (which explains why the median price is equal to the target), but because the target is so high, public stock often reaches its capacity constraint and government is forced to let the price fall below the target price, with the result that this policy often fails to defend the price-band. However, this should not be seen as a failure. The price-peg program is designed to maximize welfare. Hence failure to defend the price-peg is intentional. The target price acts as a pretext for accumulating stocks to stabilize prices and is not expected to be defended seriously. This behavior shows that a price-band achieves reasonable welfare performance only by being designed in a way that is the opposite of most expectations. In this case, it is designed so that the overall storage level (public and private) is as close as possible to what could be achieved by an optimal, state-contingent rule (figure 1).

\section{Conclusion}

In this article, we have evaluated the properties of different storage policies designed to maximize social welfare, in a model representing the cereals market in a developing country. Equilibrium without public intervention is non-optimal because consumers are risk averse and unable to insure against price risk. We consider an optimal, state-contingent policy under discretion and two optimal simple rules of storage, 
a constant subsidy to private storage and a price-band defended by public stocks limited by a capacity constraint.

Regarding simple rules of storage, the storage subsidy produces welfare results close to the discretionary policy, and the welfare gains under the price-band scheme are the lowest of all tested policies, but still represent three-quarters of the gains from the optimal policy under discretion.

A price-band policy is defined by three parameters: a floor price, a ceiling price and a capacity constraint on public storage. The parameters maximizing welfare are a floor price equal to the ceiling price and close to the non-stochastic steady state, and a capacity constraint of $11 \%$ of steady-state production. This price-peg cannot be defended indefinitely since, at some point in time, the public stock will be exhausted or will reach its capacity constraint. The target price is set so high that the capacity constraint is most often binding and government is forced to let prices decrease below the intervention level. The target price is not meant to be defended seriously, but instead is a way of forcing the accumulation of public stocks above the private stock level without intervention.

Here, simple storage rules were compared directly with a state-contingent rule for a given model. However, the potential role of the former in stabilization policies may be based also on considerations of model uncertainty. Volatility in agricultural prices is caused by shocks other than solely productivity shocks. Demand shocks, monetary shocks and input price shocks are all candidates. Although a model featuring productivity shocks associated with private storage would seem to be a good approximation for commodity price dynamics (Cafiero et al. 2011), there are uncertainties about the data generating process. There are so many uncertainties about the most appropriate model and the value of the behavioral parameters that it might be better to rely on simple rules with good performance in a variety of settings, than on a fully optimal policy designed for a specific model, but which may behave poorly in other contexts. However, a price-band may not be the answer since we have shown that it can lead to welfare losses when calibrated with slightly different parameters.

We have also neglected shocks related to international trade, which have played a crucial role in the recent food crisis (Anderson and Nelgen 2012a), by assuming a closed economy. International trade provides in addition to storage another policy instrument through trade policy adjustments. It also makes the problem more complex to handle as it adds at least one state variable, world price, and makes results dependent on the role of trade in the food market equilibrium of the economy under analysis. However, the same methods could be used in an open economy context to design optimal stabilization policies (see, e.g., Gouel and Jean 2012, for an application in the case of a normally self-sufficient country).

Lastly, the motivation for public intervention was based on consumers' risk aversion and missing insurance markets. In this welfare framework, consumers are concerned by price volatility but pay no particular attention to price spikes. An optimal policy would reduce them since they contribute to overall volatility, but reducing their frequency does not imply any consideration beyond the effect on price volatility. This issue is the object of policy debate. For example, Barrett and Bellemare (2011) suggest, in analyzing the correlation between political unrest and food price index, that price spikes matter, not volatility per se. On the other hand, most countries vary their agricultural trade policies counter-cyclically to alleviate world price movements (Anderson and Nelgen 2012b), not just price spikes, which would indicate that policy-makers are very concerned about price volatility. The focus in this article was on the relative merits of various optimal stabilization schemes, not on developing new microfoundations for price stabilization policies. However, it should be noted that the importance of price volatility for consumers' welfare has been questioned, and although the approach would be similar with a different 
welfare objective, the results in this article are a product of the assumptions of risk aversion and missing insurance market.

\section{References}

Ambler, S., and F. Pelgrin. 2010. "Time-consistent control in non-linear models." Journal of Economic Dynamics and Control 34:2215-2228.

Anderson, K., and S. Nelgen. 2012a. "Agricultural Trade Distortions During the Global Financial Crisis." Oxford Review of Economic Policy 28:235-260.

Anderson, K., and S. Nelgen. 2012b. "Trade Barrier Volatility and Agricultural Price Stabilization.” World Development 40:36-48.

Asian Development Bank. 2008. "Food Prices and Inflation in Developing Asia: Is Poverty Reduction Coming to an End?" Special report, ADB, Economics and Research Department, Manila, April.

Babcock, B.A., and D.A. Hennessy. 1996. "Input Demand under Yield and Revenue Insurance." American Journal of Agricultural Economics 78:416-427.

Barrett, C.B., and M.F. Bellemare. 2011. "Why Food Price Volatility Doesn't Matter: Policymakers Should Focus on Bringing Costs Down." Foreign Affairs July 12.

Bobenrieth, E.S.A., J.R.A. Bobenrieth, and B.D. Wright. 2004. “A Model of Supply of Storage.” Economic Development and Cultural Change 52:605-616.

Brennan, D. 2003. "Price dynamics in the Bangladesh rice market: implications for public intervention." Agricultural Economics 29:15-25.

Cafiero, C., E.S.A. Bobenrieth, J.R.A. Bobenrieth, and B.D. Wright. 2011. "The Empirical Relevance of the Competitive Storage Model." Journal of Econometrics 162:44-54.

Chavas, J.P., P.M. Despins, and T.R. Fortenbery. 2000. "Inventory Dynamics under Transaction Costs." American Journal of Agricultural Economics 82:260-273.

Clarida, R., J. Galí, and M. Gertler. 1999. "The Science of Monetary Policy: A New Keynesian Perspective." Journal of Economic Literature 37:1661-1707.

de Janvry, A., and E. Sadoulet. 2006. "Progress in the modeling of rural households' behavior under market failures." In A. de Janvry and R. Kanbur, eds. Poverty, inequality and development: essays in honor of Erik Thorbecke. New York: Springer, chap. 9, pp. 155-182.

Dorosh, P.A. 2008. "Food Price Stabilisation And Food Security: International Experience." Bulletin of Indonesian Economic Studies 44:93-114.

Fafchamps, M. 1992. "Cash Crop Production, Food Price Volatility, and Rural Market Integration in the Third World.” American Journal of Agricultural Economics 74:90-99.

Finkelshtain, I., and J.A. Chalfant. 1997. "Commodity Price Stabilization in a Peasant Economy.” American Journal of Agricultural Economics 79:1208-1217.

Gardner, B.L. 1979. "Robust Stabilization Policies for International Commodity Agreements." American Economic Review: Papers and Proceedings 69(2):169-172.

Gardner, B.L., and R. López. 1996. "The Inefficiency of Interest-Rate Subsidies in Commodity Price Stabilization." American Journal of Agricultural Economics 78:508-516.

Gilbert, C.L. 1996. "International Commodity Agreements: An obituary notice.” World Development 24:1-19.

Gouel, C. 2013. “Optimal food price stabilisation policy.” European Economic Review 57:118-134. 
Gouel, C., and S. Jean. 2012. "Optimal Food Price Stabilization in a Small Open Developing Country." Policy Research Working Paper No. 5943, The World Bank.

Hausman, J.A. 1981. "Exact Consumer's Surplus and Deadweight Loss." The American Economic Review 71:662-676.

Helms, L.J. 1985a. "Errors in the Numerical Assessment of the Benefits of Price Stabilization." American Journal of Agricultural Economics 67:93-100.

Helms, L.J. 1985b. "Expected Consumer's Surplus and the Welfare Effects of Price Stabilization." International Economic Review 26:603-617.

Keynes, J.M. 1974. "The international control of raw materials." Journal of International Economics 4:299-315, memorandum dated 14 April 1942.

Klein, P., P. Krusell, and J.V. Ríos-Rull. 2008. "Time-Consistent Public Policy.” Review of Economic Studies 75:789-808.

Kydland, F.E., and E.C. Prescott. 1977. "Rules Rather than Discretion: The Inconsistency of Optimal Plans." The Journal of Political Economy 85:473-491.

Levin, A., V. Wieland, and J.C. Williams. 2003. "The Performance of Forecast-Based Monetary Policy Rules under Model Uncertainty." The American Economic Review 93:622-645.

Miranda, M.J., and P.G. Helmberger. 1988. "The Effects of Commodity Price Stabilization Programs." The American Economic Review 78:46-58.

Nelson, C.H., and P.V. Preckel. 1989. "The Conditional Beta Distribution as a Stochastic Production Function.” American Journal of Agricultural Economics 71:370-378.

Rao, J.M. 1989. “Agricultural supply response: A survey.” Agricultural Economics 3:1-22.

Rust, J. 1987. "Optimal Replacement of GMC Bus Engines: An Empirical Model of Harold Zurcher." Econometrica 55:999-1033.

Salant, S.W. 1983. "The Vulnerability of Price Stabilization Schemes to Speculative Attack.” The Journal of Political Economy 91:1-38.

Scheinkman, J.A., and J. Schechtman. 1983. "A Simple Competitive Model with Production and Storage." Review of Economic Studies 50:427-441.

Schiff, M., and C.E. Montenegro. 1997. "Aggregate Agricultural Supply Response in Developing Countries: A Survey of Selected Issues.” Economic Development and Cultural Change 45:393-410.

Schmitt-Grohé, S., and M. Uribe. 2007. "Optimal simple and implementable monetary and fiscal rules." Journal of Monetary Economics 54:1702-1725.

Seale, J.L., Jr., and A. Regmi. 2006. "Modeling International Consumption Patterns." Review of Income and Wealth 52:603-624.

Taylor, J.B., and J.C. Williams. 2010. "Simple and Robust Rules for Monetary Policy." Amsterdam: Elsevier, vol. 3B of Handbook of Monetary Economics, chap. 15, pp. 829-859.

Timmer, C.P. 1997. "Building efficiency in agricultural marketing: The long-run role of BULOG in the Indonesian food economy." Journal of International Development 9:133-145.

Timmer, C.P. forthcoming. "Managing Price Volatility: Approaches at the global, national, and household levels." In W. P. Falcon and R. L. Naylor, eds. Stanford Synthesis Volume on Global Food Policy and Food Security in the 21st Century. Stanford Center on Food Security and the Environment, chap. 4.

Tschirley, D.L., and T.S. Jayne. 2010. "Exploring the Logic Behind Southern Africa's Food Crises." World Development 38:76-87.

Turnovsky, S.J., H. Shalit, and A. Schmitz. 1980. "Consumer's Surplus, Price Instability, and Consumer Welfare." Econometrica 48:135-152. 
von Braun, J., and M. Torero. 2009. "Implementing Physical and Virtual Food Reserves to Protect the Poor and Prevent Market Failure.” Policy Brief No. 10, IFPRI, February.

Williams, J.C., and B.D. Wright. 1991. Storage and Commodity Markets. New York: Cambridge University Press.

World Bank, and FAO. 2012. The Grain Chain: Food Security and Managing Wheat Imports in Arab Countries. Washington, DC.: World Bank.

Wright, B.D. 2012. "International Grain Reserves and Other Instruments to Address Volatility in Grain Markets." World Bank Research Observer 27:222-260.

Wright, B.D., and J.C. Williams. 1988a. "The Incidence of Market-Stabilising Price Support Schemes." The Economic Journal 98:1183-1198.

Wright, B.D., and J.C. Williams. 1988b. "Measurement of Consumer Gains from Market Stabilization." American Journal of Agricultural Economics 70:616-627.

Wright, B.D., and J.C. Williams. 1982. "The Roles of Public and Private Storage in Managing Oil Import Disruptions." The Bell Journal of Economics 13:341-353. 